\title{
DECISION MAKING WITH DEMPSTER-SHAFER BELIEF STRUCTURE AND THE OWAWA OPERATOR
}

\author{
José M. MERIGÓa ${ }^{a}$ Kurt J. ENGEMANN ${ }^{b}$, Daniel PALACIOS-MARQUÉSc \\ ${ }^{a}$ Department of Business Administration, University of Barcelona, \\ Av. Diagonal 690, 08034 Barcelona, Spain \\ ${ }^{b}$ Hagan School of Business, Iona College, 10801 New Rochelle, New York, USA \\ 'Department of Business Organisation, Universitat Politècnica de València, \\ Camino Vera s/n. 46022, València, Spain
}

Received 16 November 2011; accepted 29 September 2012

\begin{abstract}
A new decision making model that uses the weighted average and the ordered weighted averaging (OWA) operator in the Dempster-Shafer belief structure is presented. Thus, we are able to represent the decision making problem considering objective and subjective information and the attitudinal character of the decision maker. For doing so, we use the ordered weighted averaging weighted average (OWAWA) operator. It is an aggregation operator that unifies the weighted average and the OWA in the same formulation. This approach is generalized by using quasi-arithmetic means and group decision making techniques. An application of the new approach in a group decision making problem concerning political management of a country is also developed.
\end{abstract}

Keywords: decision making, OWA operator, weighted average, Dempster-Shafer belief structure, aggregation operators, political management.

Reference to this paper should be made as follows: Merigó, J. M.; Engemann, K. J.; Palacios-Marqués, D. 2013. Decision making with Dempster-Shafer belief structure and the OWAWA operator, Technological and Economic Development of Economy 19(Supplement 1): S100-S118.

JEL Classification: C44, C49, D81, D89.

\section{Introduction}

The Dempster-Shafer (D-S) theory of evidence was introduced by Dempster (1967) and by Shafer (1976). Since its introduction, this theory has been studied and applied in a lot of situations (Srivastava, Mock 2002; Yager, Liu 2008). It provides a unifying framework for representing uncertainty because it includes as special cases the situations of risk (probabil-

Corresponding author José M. Merigó

E-mail: jmerigo@ub.edu 
istic uncertainty) and ignorance (imprecision). One of the key application areas of the D-S theory is in decision making because it allows the use of risk and uncertain environments in the same framework. This model can be carried out with a lot of aggregation operators (Merigó, Casanovas 2009; Reformat, Yager 2008). Some authors (Engemann et al. 1996a; Merigó et al. 2010; Yager 1992) have considered the possibility of using the ordered weighted averaging (OWA) operator.

The OWA operator (Yager 1988) is an aggregation operator that provides a parameterized family of aggregation operators between the maximum and the minimum. Since its introduction, it has been applied in a wide range of situations (Yager, Kacprzyk 1997; Yager et al. 2011). For example, Yager (2004) developed a generalization by using generalized means and Fodor et al. (1995) by using quasi-arithmetic means. Merigó and Gil-Lafuente (2009) extended the previous approaches by using induced aggregation operators. Other extensions have considered problems with imprecise information in the analysis by using interval numbers (Merigó, Casanovas 2011a, b), fuzzy numbers (Liu 2011; Wei et al. 2010; Zhao et al. 2010) and linguistic variables (Wei 2011). Other developments have considered the use of distance measures in the aggregation process (Merigó, Gil-Lafuente 2010; Zeng, Su 2011). Zhou and Chen $(2010,2011,2012)$ have considered the use of continuous, logarithmic and power aggregation operators.

Recently, Merigó (2011) has introduced the ordered weighted averaging - weighted average (OWAWA) operator. It is an aggregation operator that unifies the weighted average (WA) and the OWA operator in the same formulation considering the degree of importance that each concept has in the aggregation. Thus, we can provide a parameterized family of aggregation operators between the minimum and the maximum that also considers the importance of the subjective information given by the weighted average. Note that this model has been further extended by adding more concepts in the formulation including the use of order inducing variables (Merigó 2011), probabilities (Merigó, Wei 2011) and generalized aggregation operators (Merigó et al. 2010).

The aim of this paper is to present a new decision making model with $\mathrm{D}$-S theory by using the OWAWA operator. The main advantage of this approach is that we are able to consider probabilistic information with WAs and OWAs in the same formulation. Thus, we are able to consider a decision making problem with objective and subjective information and considering the attitudinal character of the decision maker. For doing so, we present a new aggregation operator, the belief structure - OWAWA (BS-OWAWA) operator. It is a new aggregation operator that aggregates the belief structures with the OWAWA operator. We study some of its main properties and particular cases.

We generalize this approach by using generalized aggregation operators. We focus on the use of the quasi-arithmetic mean obtaining the quasi-arithmetic BS-OWAWA (BS-QuasiOWAWA) operator. It includes a wide range of particular cases including the generalized BS-OWAWA (BS-GOWAWA) operator because the quasi-arithmetic mean includes the generalized mean in its formulation. It also includes a lot of other aggregation operators including the quadratic BS-OWAWA (BS-OWAWQA) operator and the geometric BS-OWAWA (BS-OWAWGA) operator. 
We further extend D-S belief structure by using group decision making techniques. Thus, we are able to obtain more complete information of the problem because usually the opinion of several persons is better than the opinion of one. We introduce the multi-person BS-OWAWA (MP-BS-OWAWA) operator. Its main advantage is that it can aggregate the information of several persons in the same formulation. We generalize this approach by using quasi-arithmetic means obtaining the quasi-arithmetic MP-BS-OWAWA (MP-BSQuasi-OWAWA) operator.

We also develop an application of the new approach in a decision making problem concerning the selection of policies. We study a problem where a government is planning the fiscal policy for the next year. The main advantage of using this approach is that we are able to consider a wide range of scenarios and select the one closest with our interests. Moreover, we can represent in a more complete way the information of the problem because in a government we find different groups that give different opinions regarding the available information. And in order to properly assess it we need to use collective results that correctly represent the different opinions.

This paper is organized as follows. In Section 1, we briefly review some basic concepts regarding the D-S theory, the WA, the OWA and the OWAWA operator. In Section 2 we present the new decision making approach. Section 3 introduces the use of group decision making techniques in D-S Framework. In Section 4 we develop an application of the new approach in political decision making. The final section summarizes the main conclusions of the paper.

\section{Preliminaries}

In this section, we briefly review some basic concepts to be used throughout the paper. We analyse the Dempster-Shafer belief structure, the weighted average (WA), the OWA operator and the OWAWA operator.

\subsection{Dempster-Shafer belief structure}

The D-S theory (Dempster 1967; Shafer 1976) provides a unifying framework for representing uncertainty as it can include the situations of risk and ignorance as special cases. Note that the case of certainty is also included as it can be seen as a particular case of risk and ignorance. It can be defined as follows.

Definition 1. A D-S belief structure defined on a space $X$ consists of a collection of $n$ nonnull subsets of $X, B_{j}$ for $j=1, \ldots, n$, called focal elements and a mapping $m$, called the basic probability assignment, defined as, $m: 2^{X} \rightarrow[0,1]$ such that:

$\begin{array}{ll}\text { 1) } & m\left(B_{j}\right) \in[0,1] ; \\ \text { 2) } & \sum_{j=1}^{n} m\left(B_{j}\right)=1_{;} \\ \text {3) } & m(A)=0, \forall A \neq B_{j} .\end{array}$ 
As said before, the cases of risk and ignorance are included as special cases of belief structure in the D-S framework. For the case of risk, a belief structure is called Bayesian belief structure if it consists of $n$ focal elements such that $B_{j}=\left\{x_{j}\right\}$, where each focal element is a singleton. Then, we can see that we are in a situation of decision making under risk environment as $m\left(B_{j}\right)=P_{j}=\operatorname{Prob}\left\{x_{j}\right\}$.

The case of ignorance is found when the belief structure consists in only one focal element $B$, where $m(B)$ essentially is the decision making under ignorance environment as this focal element comprises all the states of nature. Thus, $m(B)=1$. Other special cases of belief structures such as the consonant belief structure or the simple support function are studied by Shafer (1976). Note that two important evidential functions associated with these belief structures are the measures of plausibility and belief.

\subsection{The OWA operator and the weighted average}

The OWA operator (Yager 1988) is an aggregation operator that provides a parameterized family of aggregation operators between the minimum and the maximum. In decision making it is very useful for representing the degree of optimism/pessimism of the decision maker. It can be defined as follows:

Definition 2. An OWA operator of dimension $n$ is a mapping $O W A: R^{n} \rightarrow R$ that has an associated weighting vector $W$ of dimension $n$ with $w_{j} \in[0,1]$ and $\sum_{j=1}^{n} w_{j}=1$, such that:

$$
O W A\left(a_{1}, \ldots, a_{n}\right)=\sum_{i=1}^{n} w_{j} b_{j}
$$

where $b_{j}$ is the $j$ th largest of the $a_{i}$.

Note that different properties could be studied such as the distinction between descending and ascending orders, different measures for characterizing the weighting vector and different families of OWA operators (Yager, Kacprzyk 1997; Yager et al. 2011; Zhou et al. 2012b).

The weighted average (WA) is one of the most common aggregation operators found in the literature. It has been used in a wide range of applications ( $\mathrm{Xu} 2010$ ). It can be defined as follows:

Definition 3. A WA operator of dimension $n$ is a mapping $W A: R^{n} \rightarrow R$ that has an associated weighting vector $V$, with $v_{j} \in[0,1]$ and $\sum_{i=1}^{n} v_{i}=1$, such that:

$$
W A\left(a_{1}, \ldots, a_{n}\right)=. .
$$

where $a_{i}$ represents the argument variable.

The WA operator accomplishes the usual properties of the aggregation operators. For further reading on different extensions and generalizations of the WA, see for example (Beliakov et al. 2007; Han, Liu 2011; Merigó 2012; Podvezko 2011; Zhang, Liu 2010; Zhou et al. 2011). 


\subsection{The OWAWA operator}

The ordered weighted averaging - weighted average (OWAWA) operator (Merigó 2011) is a new model that unifies the OWA operator and the weighted average in the same formulation. Therefore, both concepts can be seen as a particular case of a more general framework that considers the degree of importance that each concept has in the aggregation. It can be defined as follows:

Definition 4. An OWAWA operator of dimension $n$ is a mapping OWAWA: $R^{n} \rightarrow R$ that has an associated weighting vector $W$ of dimension $n$ such that $w_{j} \in[0,1]$ and $\sum_{j=1}^{n} w_{j}=1$,
according to the following equation:

$$
\operatorname{OWAWA}\left(a_{1}, \ldots, a_{n}\right)=\sum_{j=1}^{n} \hat{v}_{j} b_{j}
$$

where: $b_{j}$ is the $j$ th largest of the $a_{i}$, each argument $a_{i}$ has an associated weight (WA) $v_{i}$ with $\sum_{i=1}^{n} v_{i}=1$, and $v_{i} \in[0,1], \hat{v}_{j}=\beta w_{j}+(1-\beta) v_{j}$ with $\beta \in[0,1]$ and $v_{j}$ is the weight (WA) $v_{i}$ ordered according to $b_{j}$, that is, according to the $j$ th largest of the $a_{i}$.

As we can see, if $\beta=1$, we get the OWA operator and if $\beta=0$, the WA. The OWAWA operator accomplishes similar properties than the usual aggregation operators including monotonicity, idempotency and the boundary condition. Note that we can distinguish between descending and ascending orders, extend it by using mixture operators, and so on (Merigó 2011). Note also that some previous models already considered the possibility of using the WA and the OWA in the same formulation (Torra 1997; Xu, Da 2003; Yager 1998) although they did not consider the degree of importance of each concept in the analysis. Some other methods considered the use of the OWA operator with the probability (Engemann et al. 1996b, 2004; Yager et al. 1995).

Note that in order to measure the degree of optimism or pessimism of the aggregation we can use the degree of orness measure suggested by Yager (1988). Note that if we only use it in the OWA operator, we assume that we only use the degree of optimism in the OWA part, while in the weighted average we assume a neutral position based on other aspects. In this case we use:

$$
\alpha(W)=\sum_{j=1}^{n} w_{j}\left(\frac{n-j}{n-1}\right)
$$

However, it is also possible to formulate the degree of orness of the OWAWA operator as a general measure that analyzes the general tendency of the aggregation to the maximum or to the minimum. In this case we get:

$$
\alpha(\widehat{V})=\beta \sum_{j=1}^{n} w_{j}\left(\frac{n-j}{n-1}\right)+(1-\beta) \sum_{j=1}^{n} v_{j}\left(\frac{n-j}{n-1}\right) .
$$

The OWAWA operator can be applied in a wide range of fields because all the previous studies that use the weighted average or the OWA operator can be revised and extended with this new approach. The reason is that we can always reduce this model to the classical cases but usually it will add an additional interpretation of the aggregation problem. 


\section{Decision making with Dempster-Shafer theory using the OWAWA operator}

In this section we present the new decision making approach by using D-S theory and the OWAWA operator. Moreover, we also analyze the aggregation process formed and study some of its main properties.

\subsection{Decision making approach}

A new method for decision making with D-S theory is possible by using the OWAWA operator. The main advantage of this approach is that we can use probabilities, WAs and OWAs in the same formulation. Thus, we are able to represent the decision problem in a more complete way because we can use subjective and objective information in the analysis and the attitudinal character (degree of optimism) of the decision maker. The decision process can be summarized as follows.

Assume we have a decision problem in which we have a collection of alternatives $\left\{A_{1}, \ldots\right.$, $\left.A_{q}\right\}$ with states of nature $\left\{S_{1}, \ldots, S_{n}\right\} . a_{i h}$ is the payoff if the decision maker selects alternative $A_{i}$ and the state of nature is $S_{h}$. The knowledge of the state of nature is captured in terms of a belief structure $m$ with focal elements $B_{1}, \ldots, B_{r}$ and associated with each of these focal elements is a weight $m\left(B_{k}\right)$. The objective of the problem is to select the alternative which gives the best result to the decision maker. In order to do so, we should follow the following steps:

Step 1: Calculate the results of the payoff matrix.

Step 2: Calculate the belief function $m$ about the states of nature.

Step 3: Calculate the attitudinal character (or degree of orness) of the decision maker $\alpha(W)$ (Yager 1988).

Step 4: Calculate the collection of weights, $w$, to be used in the OWAWA aggregation for each different cardinality of focal elements. Note that it is possible to use different methods depending on the interests of the decision maker (Merigó 2011; Xu 2005; Yager 1993). Note also that for the WA aggregation we have to calculate the weights according to a degree of importance (or subjective probability) of each state of nature. This can be carried out by using the opinion of a group of experts that has some information about the possibility that each state of nature will occur.

Step 5: Determine the results of the collection, $M_{i k}$, if we select alternative $A_{i}$ and the focal element $B_{k}$ occurs, for all the values of $i$ and $k$. Hence $M_{i k}=\left\{a_{i h} \mid S_{h} \in B_{k}\right\}$.

Step 6: Calculate the aggregated results, $V_{i k}=O W A W A\left(M_{i k}\right)$, using Eq. (3), for all the values of $i$ and $k$.

Step 7: For each alternative, calculate the generalized expected value, $C_{i}$, where:

$$
C_{i}=\sum_{k=1}^{r} V_{i k} m\left(B_{k}\right) .
$$

Step 8: Select the alternative with the largest $C_{i}$ as the optimal. Note that in a minimization problem, the optimal choice is the lowest result.

From a generalized perspective of the reordering step, it is possible to distinguish between descending and ascending orders in the OWAWA aggregation. This is useful for example when distinguishing between minimization and maximization problems. 


\subsection{The BS-OWAWA operator}

Analyzing the aggregation in Steps 6 and 7 of the previous subsection, it is possible to formulate in one equation the whole aggregation process. We call this process the belief structure OWAWA (BS-OWAWA) aggregation. It can be defined as follows:

Definition 5. A BS-OWAWA operator is defined by:

$$
B S-O W A W A=\sum_{k=1}^{r} \sum_{j=1}^{q} m\left(B_{k}\right) \hat{v}_{j k} b_{j k}
$$

where: $\hat{v}_{j k}$ is the weighting vector of the $k$ th focal element such that $\sum_{j=1}^{q} \hat{v}_{j k}=1$ and $\hat{v}_{j k} \in$ $[0,1], b_{j k}$ is the $j k$ th largest of the $a_{i k}$, each argument $a_{i k}$ has an associated weight (WA) $v_{i k}$ with $\sum_{i=1}^{q} v_{i k}=1$ and $v_{i k} \in[0,1]$, and a weight (OWA) $w_{j k}$ with $\sum_{j=1}^{q} w_{j k}$ and $w_{j k} \in[0,1]$, $\hat{v}_{j k}=\beta w_{j k}+(1-\beta) v_{j k}$ with $\beta \in[0,1]$ and $v_{j}$ is the weight (WA) $v_{i}$ ordered according to $b_{j}$, that is, according to the $j$ th largest of the $a_{i k}$, and $m\left(B_{k}\right)$ is the basic probability assignment.

Note that $q_{k}$ refers to the cardinality of each focal element and $r$ is the total number of focal elements. The BS-OWAWA operator is monotonic, bounded and idempotent. By choosing a different manifestation in the weighting vector of the OWAWA operator, we are able to develop different families of BS-OWAWA operators (Merigó 2011; Merigó, Casanovas 2009). As it can be seen in Definition 5, each focal element uses a different weighting vector in the aggregation step with the OWAWA operator. Therefore, for each focal element, we can use a different type of OWAWA operator. For example, if $\beta=1$, we get the BS-OWA operator and if $\beta=0$, the BS-WA operator.

Remark 1. Some other cases could be used following the OWA literature (Merigó 2011; Yager 1993). For example:

- The maximum-WA if $w_{1}=1$ and $w_{j}=0$, for all $j \neq 1$;

- The minimum-WA if $w_{n}=1$ and $w_{j}=0$, for all $j \neq n$;

- The average when $w_{j}=1 / n$ and $v_{i}=1 / n$, for all $a_{i}$;

- The step-OWAWA operator when $w_{k}=1$ and $w_{j}=0$, for all $j \neq k$;

- The arithmetic-WA when $w_{j}=1 / n$ for all $j$;

- The arithmetic-OWA (A-OWA) when $v_{i}=1 / n$, for all $i$;

- The olympic-OWAWA when $w_{1}=w_{n}=0$, and for all others $w_{j^{*}}=1 /(n-2)$;

- Note that it is possible to develop a general form of the olympic-OWAWA by considering that $w_{j}=0$ for $j=1,2, \ldots, k, n, n-1, \ldots, n-k+1$, and for all others $w_{j^{*}}=1 /$ $(n-2 k)$, where $k<n / 2$;

- The centered-OWAWA when it is symmetric, strongly decaying and inclusive. It is symmetric if $\hat{v}_{j}=\hat{v}_{j+n-1}$. It is strongly decaying when $i<j \leq(n+1) / 2$ then $\hat{v}_{i}<\hat{v}_{j}$ and when $i>j \geq(n+1) / 2$ then $\hat{v}_{i}<\hat{v}_{j}$. It is inclusive if $\hat{v}_{j}>0$;

- And many others (Merigó 2011; Xu 2005; Yager 1993). 


\subsection{Generalized aggregation operators in D-S framework}

A further generalization of the previous model can be developed by using generalized aggregation operators in the analysis by using generalized means (Merigó, Gil-Lafuente 2009; Yager 2004; Zhou et al. 2012a) and quasi-arithmetic means (Fodor et al. 1995; Merigó, Casanovas 2011a). The main advantage of using these generalizations is that we can represent the information in a more complete way including a wide range of particular cases. By using generalized means in the analysis we use the generalized OWAWA (GOWAWA) operator in $\mathrm{D}-\mathrm{S}$ framework. In this case, the decision making process is very similar to the framework shown in Section 3.1 with the following differences.

In Steps 3-4, when calculating the collection of weights, $w$, we have to consider that we are using the GOWAWA operator in the aggregation for each different cardinality of focal elements.

In Step 6, when calculating the aggregated payoff, we should use $V_{i k}=\operatorname{GOWAWA}\left(M_{i k}\right)$, for all the values of $i$ and $k$.

In this case, we could also formulate in one equation the whole aggregation process as follows. We call it the BS-GOWAWA operator. Note that the formulation is the same than the $B S-O W A W A$ with the difference that now we add an additional parameter $\lambda$ that represents the use of the generalized mean in the analysis. That is:

$$
B S-G O W A W A=\sum_{k=1}^{r} m\left(B_{k}\right)\left(\beta\left(\sum_{j=1}^{q} w_{j k} b_{j k}^{\lambda}\right)^{1 / \lambda}+(1-\beta)\left(\sum_{i=1}^{q} v_{i k} a_{i k}^{\lambda}\right)^{1 / \delta}\right) \text {, }
$$

where $\lambda$ is a parameter such that $\lambda \in(-\infty, \infty)-\{0\}$.

If we use quasi-arithmetic means in the model, we are using the quasi-arithmetic OWAWA (Quasi-OWAWA) operator in D-S belief structure. Thus, the decision process is very similar than the previous one with the difference that now instead of using generalized means, we use quasi-arithmetic means. Thus, in Step 6 we should use $V_{i k}=$ Quasi-OWAWA $\left(M_{i k}\right)$, for all the values of $i$ and $k$.

If we formulate this approach in one equation, the model is the same with the difference that we replace the parameter $\lambda$ by a strictly continuous monotonic function $g(b)$ obtaining the BS-Quasi-OWAWA operator. That is:

$$
B S-Q u a s i-O W A W A=\sum_{k=1}^{r} m\left(B_{k}\right)\left(\beta g^{-1}\left(\sum_{j=1}^{q} w_{j k} g\left(b_{j k}\right)\right)+(1-\beta) h^{-1}\left(\sum_{i=1}^{q} v_{i k} h\left(a_{i k}\right)\right)\right) \text {, }
$$

where $g(b)$ is a strictly continuous monotonic function.

As said before, the main advantage of these models is that they include a wide range of particular cases including the BS-OWAWA operator, the $B S-W A$ and the $B S-O W A$ operator.

Remark 2. For example, the BS-OWAWA operator is found when $\lambda=\delta=1$ or $g(b)=$ $h(a)=b$. That is:

$$
B S-O W A W A=\sum_{k=1}^{r} m\left(B_{k}\right)\left(\beta\left(\sum_{j=1}^{q} w_{j k} b_{j k}\right)+(1-\beta)\left(\sum_{i=1}^{q} v_{i k} a_{i k}\right)\right) .
$$

Note that Eq. (10) is equivalent to Eq. (7). 
Remark 3. If $\lambda=\delta=2$ or $g(b)=h(a)=b^{2}$, we get the quadratic BS-OWAWA (BSOWAWQA) operator:

$$
B S-O W A W Q A=\sum_{k=1}^{r} m\left(B_{k}\right)\left(\beta\left(\sum_{j=1}^{q} w_{j k} b_{j k}^{2}\right)^{1 / 2}+(1-\beta)\left(\sum_{i=1}^{q} v_{i k} a_{i k}^{2}\right)^{1 / 2}\right) .
$$

Remark 4. If $\lambda=\delta=3$ or $g(b)=h(a)=b^{3}$, we get the cubic BS-OWAWA (BS-OWAWCA) operator:

$$
B S-O W A W C A=\sum_{k=1}^{r} m\left(B_{k}\right)\left(\beta\left(\sum_{j=1}^{q} w_{j k} b_{j k}^{3}\right)^{1 / 3}+(1-\beta)\left(\sum_{i=1}^{q} v_{i k} a_{i k}^{3}\right)^{1 / 3}\right) .
$$

Remark 5. If $\lambda=\delta \rightarrow 0$ or $g(b)=h(a) \rightarrow b^{0}$, we get the geometric BS-OWAWA (BSOWAWGA) operator:

$$
B S-O W A W G A=\sum_{k=1}^{r} m\left(B_{k}\right)\left(\beta\left(\sum_{j=1}^{q} b_{j k}^{w_{j k}}\right)+(1-\beta)\left(\sum_{i=1}^{q} a_{i k}^{v_{i k}}\right)\right) .
$$

Note that more complex situations could be formed by using different values in the parameter $\lambda(O W A)$ and $\delta(W A)$ and in the function $g(O W A)$ and $h(W A)$. Moreover, we could also assume that the probabilities given by the focal elements can also be extended with generalized and quasi-arithmetic means.

\section{Group decision making with Dempster-Shafer theory}

In the previous framework, we assume that the information is assessed by one decision maker. However, in real-world problems it is very common that the decisions are assessed by a group of persons. This is especially relevant when considering macrodecisions with very strong implications that need very serious assessments in order to obtain the most appropriate selection such as decisions concerning the variation of the interest rate of the European Central Bank, the European Constitution and variations in the taxes of a country.

Note that in the next section we will analyze a problem in political decision making where it is very common to make group decisions because generally, the decision of a group is better than the decision of a person because the knowledge provided by a group is higher. Typical examples are the decisions made in the parliament of a country or in the ministries council.

The procedure to follow when making group decisions with Dempster-Shafer theory of evidence and the OWAWA operator can be summarized as follows. Note that many other decision-making models have been discussed in the literature (Antuchevičienè et al. 2010; Brauers, Zavadskas 2010; Engemann, Miller 2009; Keršulienè et al. 2010; Liu 2009; Podvezko 2009; Zavadskas, Turskis 2011; Zavadskas et al. 2010a, b).

Assume we have a decision problem in which we have a collection of alternatives $\left\{A_{1}\right.$, $\left.\ldots, A_{q}\right\}$ with states of nature $\left\{S_{1}, \ldots, S_{n}\right\}$ forming the payoff matrix $\left(a_{h i}\right)_{m \times n}$. Let $E=\left\{e_{1}, e_{2}, \ldots\right.$, $\left.e_{p}\right\}$ be a finite set of decision-makers. Let $U=\left(u_{1}, u_{2}, \ldots, u_{p}\right)$ be the weighting vector of the 
decision-makers such that $\sum_{t=1}^{p} u_{t}=1$ and $u_{t} \in[0,1]$. Each decision-maker provides his own payoff matrix $\left(a_{h i}{ }^{(t)}\right)_{m \times n}$. The knowledge of the state of nature is captured in terms of a belief structure $m$ with focal elements $B_{1}, \ldots, B_{r}$ and associated with each of these focal elements is a weight $m\left(B_{k}\right)$. The objective of the problem is to select the alternative that gives the best result to the decision maker. In order to do so, we should follow the following steps:

Step 1: Construct $p$ individual payoff matrices according to the information given by each decision-maker of the group.

Step 2: Use the WA to aggregate the information of the decision-makers $E$ using the weighting vector $U$. The result is the collective payoff matrix $\left(a_{h i}\right)_{m \times n}$. Thus, $a_{h i}=\sum_{t=1}^{p} u_{t} a_{h i}^{t}$. Note that it is possible to use other types of OWAWA operators instead of the WA to aggregate this information.

Step 3: Calculate the belief function $m$ about the states of nature.

Step 4: Calculate the attitudinal character (or degree of orness) of the decision maker $\alpha(W)$ (Yager 1988) using Eq. (4) and Eq. (5).

Step 5: Calculate the collection of weights, $w$, to be used in the OWAWA aggregation $(\widehat{V}=\beta \times W+(1-\beta) \times V)$ for each different cardinality of focal elements. Note that $W=\left(w_{1}\right.$, $\left.w_{2}, \ldots, w_{n}\right)$ such that $\sum_{j=1}^{n} w_{j}=1$ and $w_{j} \in[0,1]$ and $V=\left(v_{1}, v_{2}, \ldots, v_{n}\right)$ such that $\sum_{i=1}^{n} w_{i}=1$ and $v_{i} \in[0,1]$.

Step 6: Determine the results of the collection, $M_{i k}$, if we select alternative $A_{i}$ and the focal element $B_{k}$ occurs, for all the values of $i$ and $k$. Hence $M_{i k}=\left\{a_{i h} \mid S_{h} \in B_{k}\right\}$.

Step 7: Calculate the aggregated results, $V_{i k}=O W A W A\left(M_{i k}\right)$, using Eq. (3), for all the values of $i$ and $k$. Consider different families of OWAWA operators as described in Section 3 in order to provide a complete representation of the information.

Step 8: For each alternative, calculate the generalized expected value, $C_{i}$, where:

$$
C_{i}=\sum_{k=1}^{r} V_{i k} m\left(B_{k}\right)
$$

Step 9: Select the alternative with the largest $C_{i}$ as the optimal. Note that in a minimization problem, the optimal choice is the lowest result.

This aggregation process can be summarized using the following aggregation operator that we call the multi-person - BS-OWAWA (MP-BS-OWAWA) operator.

Definition 6. A MP-BS-OWAWA operator is a mapping $M P-B S-O W A W A: R^{n} \times R^{p} \times R^{r} \rightarrow$ $R$ that has a weighting vector $U$ of dimension $p$ with $\sum_{k=1}^{p} u_{p}=1$ and $u_{k} \in[0,1]$, such that:

$$
M P-B S-O W A W A\left(\left(a_{1}^{1}, \ldots, a_{1}^{p}\right), \ldots,\left(a_{n}^{1}, \ldots, a_{n}^{p}\right)\right)=\sum_{k=1}^{r} \sum_{j=1}^{q} m\left(B_{k}\right) \hat{v}_{j k} b_{j k},
$$

where: $\hat{v}_{j k}$ is the weighting vector of the $k$ th focal element such that $\sum_{j=1}^{q} \hat{v}_{j k}=1$ and $\hat{v}_{j k} \in$ $[0,1], b_{j k}$ is the $j k$ th largest of the $a_{i k}$, each argument $a_{i k}$ has an associated weight $(W A) v_{i k}$ 
with $\sum_{i=1}^{k} v_{i k}=1$ and $v_{i k} \in[0,1]$, and a weight $(O W A) w_{j k}$ with $\sum_{j=1}^{q} w_{j k}=1$ and $w_{j k} \in[0,1]$, $\hat{v}_{j k}=\beta w_{j k}+(1-\beta) v_{j k}$ with $\beta \in[0,1]$ and $v_{j}$ is the weight $(W A) v_{i}$ ordered according to $b_{j}$, that is, according to the jth largest of the $a_{i k} a_{i k}=\sum_{t=1}^{p} u_{t} a_{i k}^{t}, a_{i k}^{t}$ is the argument variable provided by each person (or expert), and $m\left(B_{k}\right)$ is the basic probability assignment.

Note that the MP-BS-OWAWA operator has similar properties to those explained in Section 3, such as the distinction between descending and ascending orders, and so on.

The $M P-B S-O W A W A$ operator includes a wide range of particular cases following the methodology explained in Section 3. Thus, it includes:

The multi-person $-B S-W A(M P-B S-W A)$ operator: When $\beta=0$.

The multi-person $-B S-O W A(M P-B S-O W A)$ operator: When $\beta=1$.

The multi-person $-B S$-arithmetic mean $(M P-B S-A M)$ operator: When $w_{j}=1 / n$ and $v_{i}=$ $1 / n$, for all $a_{i}$.

The multi-person - BS-arithmetic-WA (MP-BS-AWA) operator: When $w_{j}=1 / n$ for all $j$.

The multi-person $-B S$-arithmetic-OWA $(M P-B S-A O W A)$ operator: When $v_{i}=1 / n$, for all $i$.

Note that if $t=1$, we obtain the BS-OWAWA operator because we assume that we only have one decision maker in the aggregation.

Note that it is possible to consider more complex situations by using different types of aggregation operators to aggregate the experts' opinions (Merigó 2011; Merigó, Gil-Lafuente 2009) and by analyzing different types of belief structures (Shafer 1976; Yager, Liu 2008).

Furthermore, it is possible generalize the $M P-B S-O W A W A$ operator by using generalized aggregation operators. By using quasi-arithmetic means (Fodor et al. 1995; Merigó, Casanovas 2011a) we obtain the quasi-arithmetic MP-BS-OWAWA (MP-BS-Quasi-OWAWA) operator. It is very similar to the MP-BS-OWAWA operator with the difference that we add a strictly continuous monotonic function for the WA and the OWA that includes a wide range of particular cases including quadratic and geometric aggregations. It can be formulated as:

$$
\begin{aligned}
& M P-B S-\text { Quasi-OWAWA }\left(\left(a_{1}^{1}, \ldots, a_{1}^{p}\right), \ldots,\left(a_{n}^{1}, \ldots, a_{n}^{p}\right)\right)= \\
& \sum_{k=1}^{r} m\left(B_{k}\right)\left(\beta g^{-1}\left(\sum_{j=1}^{q} w_{j k} g\left(b_{j k}\right)\right)+(1-\beta) h^{-1}\left(\sum_{i=1}^{q} v_{i k} h\left(a_{i k}\right)\right)\right),
\end{aligned}
$$

where $g$ and $h$ are strictly continuous monotonic functions.

Remark 6. Some interesting particular cases of the MP-BS-Quasi-OWAWA operator can be formed as follows:

Note that if $g(b)=b^{\lambda}$ and $h(a)=a^{\delta}$, we obtain the generalized MP-BS-OWAWA (MP$B S-G O W A W A$ ) operator.

Quadratic MP-BS-OWAWA (MP-BS-OWAWQA) operator: When $g(b)=b^{2}$ and $h(a)=a^{2}$. Cubic MP-BS-OWAWA (MP-BS-OWAWCA) operator: When $g(b)=b^{2}$ and $h(a)=a^{2}$. Geometric MP-BS-OWAWA (MP-BS-OWAWGA) operator: When $g(b) \rightarrow b^{0}$ and $h(a) \rightarrow a^{0}$. 


\section{Application in political management}

This new approach can be implemented in a wide range of decision making problems including strategic decision making, investment selection, political management and juridical decision making. In this paper, we focus on an application in political decision making regarding the selection of the optimal fiscal policy in a country/region by using the OWAWA operator and Dempster-Shafer belief structure.

Assume a government that it is planning his fiscal policy for the next year and considers five possible alternatives:

- $A_{1}=$ Develop a strong expansive fiscal policy;

- $A_{2}=$ Develop an expansive fiscal policy;

- $A_{3}=$ Do not make any change;

- $A_{4}=$ Develop a contractive fiscal policy;

- $A_{5}=$ Develop a strong contractive fiscal policy.

In order to evaluate these fiscal policies, the group of experts of the government considers that the key factor is the economic situation of the world for the next year. After careful analysis, the experts have considered five possible situations that could happen in the future:

- $S_{1}=$ Very bad economic situation;

- $S_{2}=$ Bad economic situation;

- $S_{3}=$ Regular economic situation;

- $S_{4}=$ Good economic situation;

- $S_{5}=$ Very good economic situation.

The group of experts of the government can be divided in 3 groups, each providing its own opinion. Depending on the situation that could happen in the future, each group of experts establish its opinion concerning the payoff matrix. The results are shown in Tables 1,2 and 3.

Table 1. Payoff matrix - Expert 1

\begin{tabular}{llllll}
\hline & $S_{1}$ & $S_{2}$ & $S_{3}$ & $S_{4}$ & $S_{5}$ \\
\hline$A_{1}$ & 30 & 70 & 90 & 30 & 30 \\
$A_{2}$ & 20 & 60 & 70 & 50 & 50 \\
$A_{3}$ & 60 & 50 & 60 & 90 & 80 \\
$A_{4}$ & 40 & 90 & 90 & 70 & 40 \\
$A_{5}$ & 60 & 50 & 30 & 50 & 70 \\
\hline
\end{tabular}

Table 2. Payoff matrix - Expert 2

\begin{tabular}{llllll}
\hline & $S_{1}$ & $S_{2}$ & $S_{3}$ & $S_{4}$ & $S_{5}$ \\
\hline$A_{1}$ & 90 & 20 & 60 & 70 & 60 \\
$A_{2}$ & 30 & 60 & 90 & 50 & 80 \\
$A_{3}$ & 20 & 40 & 30 & 30 & 80 \\
$A_{4}$ & 40 & 50 & 90 & 70 & 30 \\
$A_{5}$ & 10 & 50 & 30 & 80 & 80 \\
\hline
\end{tabular}


Table 3 Payoff matrix - Expert 3

\begin{tabular}{llllll}
\hline & $S_{1}$ & $S_{2}$ & $S_{3}$ & $S_{4}$ & $S_{5}$ \\
\hline$A_{1}$ & 90 & 80 & 80 & 30 & 60 \\
$A_{2}$ & 50 & 60 & 90 & 50 & 80 \\
$A_{3}$ & 60 & 20 & 50 & 70 & 80 \\
$A_{4}$ & 40 & 10 & 90 & 70 & 50 \\
$A_{5}$ & 70 & 50 & 70 & 80 & 60 \\
\hline
\end{tabular}

In this example, we assume the following weighting vector for the three groups of experts: $U=(0.4,0.3,0.3)$ representing the degree of importance they have in the analysis. Thus, we can aggregate their opinions obtaining a single collective payoff matrix that represents the aggregated information of the previous Tables. The results are shown in Table 4.

Table 4. Payoff matrix - Collective result

\begin{tabular}{llllll}
\hline & $S_{1}$ & $S_{2}$ & $S_{3}$ & $S_{4}$ & $S_{5}$ \\
\hline$A_{1}$ & 70 & 60 & 80 & 40 & 50 \\
$A_{2}$ & 30 & 60 & 80 & 50 & 70 \\
$A_{3}$ & 50 & 40 & 50 & 70 & 80 \\
$A_{4}$ & 40 & 60 & 90 & 70 & 40 \\
$A_{5}$ & 50 & 50 & 40 & 70 & 70 \\
\hline
\end{tabular}

After careful analysis of the information, the experts have obtained some general probabilistic information about which state of nature will happen in the future although there is no specific probability for each state of nature. This information is based on historical data and several experiments made by the experts. Due to the high degree of uncertainty involved, they can only provide the probabilistic information in the form of a belief structure. This information is represented by the following belief structure about the states of nature.

Focal element

$$
\begin{aligned}
& B_{1}=\left\{S_{1}, S_{2}, S_{3}\right\}=0.3 ; \\
& B_{2}=\left\{S_{1}, S_{3}, S_{5}\right\}=0.3 ; \\
& B_{3}=\left\{S_{3}, S_{4}, S_{5}\right\}=0.4 .
\end{aligned}
$$

The attitudinal character of the government is very complex because it involves the opinion of several political parties with different interests. After careful evaluation, the experts establish the following weighting vectors for both the $W A$ and the $O W A$ operator: $W=(0.2$, $0.4,0.4)$ and $V=(0.3,0.3,0.4)$. It is worth noting that for the $O W A$ we assume a weighting vector that tends to be a bit pessimistic with the assumption that the government wants to make a safety decision. Note that they assume that the OWA has a degree of importance of $30 \%$ and the $W A$ a degree of $70 \%$. With this information, we can obtain the aggregated results. In this example, apart from considering the results obtained with the OWAWA operator, we 
also consider the results obtained with the maximum, minimum, the Min-WA, the MaxWA, the arithmetic mean, the weighted average and the OWA operator. Thus, we can get a more complete picture of the potential situations that may occur in the future. They are shown in Table 5.

Table 5. Aggregated results

\begin{tabular}{ccccccccc}
\hline & Min & Max & Min-WA & Max-WA & $A M$ & $W A$ & OWA & OWAWA \\
\hline$V_{11}$ & 60 & 80 & 67.7 & 73.7 & 70 & 71 & 68 & 70.1 \\
$V_{12}$ & 50 & 80 & 60.5 & 69.5 & 66.6 & 65 & 64 & 64.7 \\
$V_{13}$ & 40 & 80 & 51.2 & 63.2 & 56.6 & 56 & 52 & 54.8 \\
$V_{21}$ & 30 & 80 & 50.3 & 65.3 & 56.6 & 59 & 52 & 56.9 \\
$V_{22}$ & 30 & 80 & 51.7 & 66.7 & 60 & 61 & 56 & 59.5 \\
$V_{23}$ & 50 & 80 & 61.9 & 70.9 & 66.6 & 67 & 64 & 66.1 \\
$V_{31}$ & 40 & 50 & 44.9 & 47.9 & 46.6 & 47 & 46 & 46.7 \\
$V_{32}$ & 50 & 80 & 58.4 & 67.4 & 60 & 62 & 56 & 60.2 \\
$V_{33}$ & 50 & 80 & 62.6 & 71.6 & 66.6 & 68 & 64 & 66.8 \\
$V_{41}$ & 40 & 90 & 58.2 & 73.2 & 63.3 & 66 & 58 & 63.6 \\
$V_{42}$ & 40 & 90 & 50.5 & 65.5 & 56.6 & 55 & 50 & 53.5 \\
$V_{43}$ & 40 & 90 & 56.8 & 71.8 & 66.6 & 64 & 62 & 63.4 \\
$V_{51}$ & 40 & 50 & 44.2 & 47.2 & 46.6 & 46 & 46 & 46 \\
$V_{52}$ & 40 & 70 & 50.5 & 59.5 & 53.3 & 55 & 50 & 53.5 \\
$V_{53}$ & 40 & 70 & 54.7 & 63.7 & 60 & 61 & 58 & 60.1 \\
\hline
\end{tabular}

Once we have the aggregated results, we have to calculate the generalized expected value. The results are shown in Table 6.

Table 6. Generalized expected value

\begin{tabular}{ccccccccc}
\hline & Min & Max & Min-WA & Max-WA & $A M$ & $W A$ & OWA & OWAWA \\
\hline$A_{1}$ & 49 & 80 & 58.94 & 68.24 & 63.62 & 63.2 & 60.4 & 62.36 \\
$A_{2}$ & 38 & 80 & 55.36 & 67.96 & 61.62 & 62.8 & 58 & 61.36 \\
$A_{3}$ & 47 & 71 & 56.1 & 63.3 & 58.62 & 60 & 56.2 & 58.79 \\
$A_{4}$ & 40 & 90 & 55.33 & 70.33 & 62.61 & 61.9 & 57.2 & 60.49 \\
$A_{5}$ & 40 & 64 & 50.29 & 57.49 & 54 & 54.7 & 52 & 53.89 \\
\hline
\end{tabular}

As we can see, depending on the aggregation operator used, the results and decisions may be different. Note that in this case, our optimal choice is the same for all the aggregation operators but in other situations we may find different decisions between each aggregation operator.

A further interesting issue is to establish an ordering of the policies. Note that this is very useful when the decision maker wants to consider more than one alternative. The results are shown in Table 7. 
Table 7. Ranking of the policies

\begin{tabular}{cc}
\hline & Ranking \\
\hline Min & $\left.\left.\left.A_{1}\right\} A_{3}\right\} A_{4}=A_{5}\right\} A_{2}$ \\
Max & $\left.\left.\left.A_{4}\right\} A_{1}=A_{2}\right\} A_{3}\right\} A_{5}$ \\
Min- WA & $\left.\left.\left.\left.A_{1}\right\} A_{3}\right\} A_{2}\right\} A_{4}\right\} A_{5}$ \\
Max-WA & $\left.\left.\left.\left.A_{4}\right\} A_{1}\right\} A_{2}\right\} A_{3}\right\} A_{5}$ \\
AM & $\left.\left.\left.\left.A_{1}\right\} A_{4}\right\} A_{2}\right\} A_{3}\right\} A_{5}$ \\
$W A$ & $\left.\left.\left.\left.A_{1}\right\} A_{2}\right\} A_{4}\right\} A_{3}\right\} A_{5}$ \\
OWA & $\left.\left.\left.\left.A_{1}\right\} A_{2}\right\} A_{4}\right\} A_{3}\right\} A_{5}$ \\
OWAWA & $\left.\left.\left.\left.A_{1}\right\} A_{2}\right\} A_{4}\right\} A_{3}\right\} A_{5}$ \\
\hline
\end{tabular}

It is worth noting that different alternatives may be optimal depending on the assumptions we assume regarding the uncertainty. Note that in this example the optimal choice seems to be $A_{1}$, although in some extreme optimistic situations we could find that $A_{4}$ is optimal. Moreover, we also find differences in the ranking process since each alternative may be ranked in a different position according to the aggregation process used in the analysis.

\section{Conclusions}

We have presented a new decision making approach with $\mathrm{D}$-S belief structure by using the OWAWA operator. The main advantage of this approach is that it deals with probabilities, WAs and OWAs in the same framework. Therefore, we are able to consider subjective and objective information and the attitudinal character of the decision maker. For doing so, we have developed the BS-OWAWA operator. It is a new aggregation operator that uses belief structures with the OWAWA operator. We have studied several families of BS-OWAWA operators and we have seen that it contains the OWA and the WA aggregation as particular cases. Moreover, by using the OWAWA we can consider a wide range of inter medium results giving different degrees of importance to the WA and the OWA.

We have further generalized this approach by using generalized aggregation operators obtaining the BS-GOWAWA and the BS-Quasi-OWAWA operators. Their key advantage is that they include a wide range of particular cases including the BS-OWAWA operator, the $B S-O W A W Q A$ operator and many others. We have also extended this approach to group decision making problems where the decisions are taken by a group instead of an individual person. We have introduced the $M P-B S-O W A W A$ operator and the $M P-B S-Q u a s i-O W A W A$ operator. We have seen that they include a wide range of cases including the $M P-B S-W A$ and the $M P-B S-O W A$.

We have also developed an application in political management by using the new approach. We have focused on a decision making problem regarding the selection of fiscal policies in a country. The main advantage of this approach is that it provides a more complete representation of the decision process because the decision maker can consider many different scenarios depending on his interests by dealing with probabilities, weighted averages and OWA operators. 
In future research, we expect to develop further extensions of this approach by considering more complex aggregation operators such as those that use uncertain information, order-inducing variables or unified aggregation operators. We will also consider other decision making applications including strategic management and investment selection.

\section{Acknowledgements}

We would like to thank the anonymous reviewers for valuable comments that have improved the quality of the paper. Support from the Spanish Ministry of Education under project "JC2009-00189", the University of Barcelona (099311) and the European Commission (PIEFGA-2011-300062) is gratefully acknowledged.

\section{References}

Antuchevičienė, J.; Zavadskas, E. K.; Zakarevičius, A. 2010. Multiple criteria construction management decisions considering relations between criteria, Technological and Economic Development of Economy 16(1): 109-125. http://dx.doi.org/10.3846/tede.2010.07

Beliakov, G.; Pradera, A.; Calvo, T. 2007. Aggregation functions: a guide for practitioners. Berlin: Springer-Verlag.

Brauers, W. K. M.; Zavadskas, E. K. 2010. Project management by MULTIMOORA as an instrument for transition economies, Technological and Economic Development of Economy 16(1): 5-24. http://dx.doi.org/10.3846/tede.2010.01

Dempster, A. P. 1967. Upper and lower probabilities induced by a multi-valued mapping, Annals of Mathematical Statistics 38(2): 325-339. http://dx.doi.org/10.1214/aoms/1177698950

Engemann, K. J.; Miller, H. E.; Yager, R. R. 1996a. Decision making with belief structures: an application in risk management, International Journal of Uncertainty, Fuzziness and Knowledge-Based Systems 4(1): 1-26. http://dx.doi.org/10.1142/S0218488596000020

Engemann, K. J.; Filev, D. P.; Yager, R. R. 1996b. Modelling decision making using immediate probabilities, International Journal of General Systems 24(3): 281-294. http://dx.doi.org/10.1080/03081079608945123

Engemann, K. J.; Miller, H. E.; Yager, R. R. 2004. Decision making with attitudinal based expected values, International Journal of Technology, Policy and Management 4(4): 353-365. http://dx.doi.org/10.1504/IJTPM.2004.006617

Engemann, K. J.; Miller, H. E. 2009. Critical infrastructure and smart technology risk modelling using computational intelligence, International Journal of Business Continuity and Risk Management 1(1): 91-111. http://dx.doi.org/10.1504/IJBCRM.2009.028953

Fodor, J.; Marichal, J. L.; Roubens, M. 1995. Characterization of the ordered weighted averaging operators, IEEE Transactions on Fuzzy Systems 3(2): 236-240. http://dx.doi.org/10.1109/91.388176

Han, Z.; Liu, P. 2011. A fuzzy multi-attribute decision-making method under risk with unknown attribute weights, Technological and Economic Development of Economy 17(2): 246-258. http://dx.doi.org/10.3846/20294913.2011.580575

Keršuliene, V.; Zavadskas, E. K.; Turskis, Z. 2010. Selection of rational dispute resolution method by applying new step-wise weight assessment ratio analysis (SWARA), Journal of Business Economics and Management 11(2): 243-258. http://dx.doi.org/10.3846/jbem.2010.12

Liu, P. 2009. Multi-attribute decision-making method research based on interval vague set and TOPSIS method, Technological and Economic Development of Economy 15(3): 453-463. 
Liu, P. 2011. A weighted aggregation operators multi-attribute group decision making method based on interval-valued trapezoidal fuzzy numbers, Expert Systems with Applications 38(2): 1053-1060. http://dx.doi.org/10.1016/j.eswa.2010.07.144

Merigó, J. M. 2011. A unified model between the weighted average and the induced OWA operator, Expert Systems with Applications 38(9): 11560-11572. http://dx.doi.org/10.1016/j.eswa.2011.03.034

Merigó, J. M. 2012. The probabilistic weighted average and its application in multi-person decision making, International Journal of Intelligent Systems 27(5): 457-476. http://dx.doi.org/10.1002/int.21531

Merigó, J. M.; Casanovas, M. 2009. Induced aggregation operators in decision making with Dempster-Shafer belief structure, International Journal of Intelligent Systems 24(8): 934-954. http://dx.doi.org/10.1002/int.20368

Merigó, J. M.; Casanovas, M. 2011a. The uncertain induced quasi-arithmetic OWA operator, International Journal of Intelligent Systems 26(1): 1-24. http://dx.doi.org/10.1002/int.20444

Merigó, J. M.; Casanovas, M. 2011b. The uncertain generalized OWA operator and its application in financial decision making, International Journal of Information Technology and Decision Making 10(2): 211-230. http://dx.doi.org/10.1142/S0219622011004300

Merigó, J. M.; Casanovas, M.; Martínez, L. 2010. Linguistic aggregation operators for linguistic decision making based on the Dempster-Shafer theory of evidence, International Journal of Uncertainty, Fuzziness and Knowledge-Based Systems 18(3): 287-304. http://dx.doi.org/10.1142/S0218488510006544

Merigó, J. M.; Gil-Lafuente, A. M. 2009. The induced generalized OWA operator, Information Sciences 179(6): 729-741. http://dx.doi.org/10.1016/j.ins.2008.11.013

Merigó, J. M.; Gil-Lafuente, A. M. 2010. New decision making techniques and their application in the selection of financial products, Information Sciences 180(11): 2085-2094. http://dx.doi.org/10.1016/j.ins.2010.01.028

Merigó, J. M.; Wei, G. W. 2011. Probabilistic aggregation operators and their application in uncertain multi-person decision making, Technological and Economic Development of Economy 17(2):335-351. http://dx.doi.org/10.3846/20294913.2011.584961

Podvezko, V. 2009. Application of AHP technique, Journal of Business Economics and Management 10(2): 181-189. http://dx.doi.org/10.3846/1611-1699.2009.10.181-189

Podvezko, V. 2011. The comparative analysis of MCDA methods SAW and COPRAS, Inzinerine Ekonomika - Engineering Economics 22(2): 134-146.

Reformat, M.; Yager, R. R. 2008. Building ensemble classifiers using belief functions and OWA operators, Soft Computing 12(6): 543-558. http://dx.doi.org/10.1007/s00500-007-0227-2

Shafer, G. A. 1976. Mathematical theory of evidence. New Jersey: Princeton University Press.

Srivastava, R. P.; Mock, T. 2002. Belief functions in business decisions. Heidelberg: Physica-Verlag. http://dx.doi.org/10.1007/978-3-7908-1798-0

Torra, V. 1997. The weighted OWA operator, International Journal of Intelligent Systems 12(2): 153-166. http://dx.doi.org/10.1002/(SICI)1098-111X(199702)12:2<153::AID-INT3>3.0.CO;2-P

Wei, G. W. 2011. Some generalized aggregation operators with linguistic information and their application to multiple attribute group decision making, Computers \& Industrial Engineering 61(1): 32-38. http://dx.doi.org/10.1016/j.cie.2011.02.007

Wei, G. W.; Zhao, X.; Lin, R. 2010. Some induced aggregating operators with fuzzy number intuitionistic fuzzy information and their applications to group decision making, International Journal of Computational Intelligence Systems 3(1): 84-95. http://dx.doi.org/10.2991/ijcis.2010.3.1.8

$\mathrm{Xu}, \mathrm{Z}$. S. 2005. An overview of methods for determining OWA weights, International Journal of Intelligent Systems 20(8): 843-865. http://dx.doi.org/10.1002/int.20097

$\mathrm{Xu}, \mathrm{Z}$. S. 2010. A deviation-based approach to intuitionistic fuzzy multiple attribute group decision making, Group Decision and Negotiation 19(1): 57-76. http://dx.doi.org/10.1007/s10726-009-9164-Z 
Xu, Z. S.; Da, Q. L. 2003. An overview of operators for aggregating information, International Journal of Intelligent Systems 18(9): 953-969. http://dx.doi.org/10.1002/int.10127

Yager, R. R. 1988. On ordered weighted averaging aggregation operators in multi-criteria decision making, IEEE Transactions on Systems, Man and Cybernetics B 18(1): 183-190. http://dx.doi.org/10.1109/21.87068

Yager, R. R. 1992. Decision making under Dempster-Shafer uncertainties, International Journal of General Systems 20(3): 233-245. http://dx.doi.org/10.1080/03081079208945033

Yager, R. R. 1993. Families of OWA operators, Fuzzy Sets and Systems 59(2): 125-148. http://dx.doi.org/10.1016/0165-0114(93)90194-M

Yager, R. R. 1998. Including importances in OWA aggregation using fuzzy systems modelling, IEEE Transactions on Fuzzy Systems 6(2): 286-294. http://dx.doi.org/10.1109/91.669028

Yager, R. R. 2004. Generalized OWA aggregation operators, Fuzzy Optimization and Decision Making 3(1): 93-107. http://dx.doi.org/10.1023/B:FODM.0000013074.68765.97

Yager, R. R.; Engemann, K. J.; Filev, D. P. 1995. On the concept of immediate probabilities, International Journal of Intelligent Systems 10(4): 373-397. http://dx.doi.org/10.1002/int.4550100403

Yager, R. R.; Kacprzyk, J. 1997. The ordered weighted averaging operators: theory and applications. Norwell, MA: Kluwer Academic Publishers. http://dx.doi.org/10.1007/978-1-4615-6123-1

Yager, R. R., Kacprzyk, J., Beliakov, G. 2011. Recent developments on the ordered weighted averaging operators: theory and practice. Berlin: Springer-Verlag. http://dx.doi.org/10.1007/978-3-642-17910-5

Yager, R. R.; Liu, L. 2008. Classic works of the Dempster-Shafer theory of belief functions. Berlin: Springer-Verlag. http://dx.doi.org/10.1007/978-3-540-44792-4

Zavadskas, E. K.; Turskis, Z. 2011. Multiple criteria decision making (MCDM) methods in economics: an overview, Technological and Economic Development of Economy 17(2): 397-427. http://dx.doi.org/10.3846/20294913.2011.593291

Zavadskas, E. K.; Turskis, Z.; Ustinovichius, L.; Shevchenko, G. 2010a. Attributes weights determining peculiarities in multiple attribute decision making methods, Inzinerine Ekonomika - Engineering Economics 21(1): 32-43.

Zavadskas, E. K.; Vilutiene, T.; Turskis, Z.; Tamosaitiene, J. 2010b. Contractor selection for construction works by applying SAW-G and TOPSIS grey techniques, Journal of Business Economics and Management 11(1): 34-55. http://dx.doi.org/10.3846/jbem.2010.03

Zeng, S.; Su, W. 2011. Intuitionistic fuzzy ordered weighted distance operator, Knowledge-Based Systems 24(8): 1224-1232. http://dx.doi.org/10.1016/j.knosys.2011.05.013

Zhang, X.; Liu, P. 2010. Method for aggregating triangular fuzzy intuitionistic fuzzy information and its application to decision making, Technological and Economic Development of Economy 16(2): 280-290. http://dx.doi.org/10.3846/tede.2010.18

Zhao, H.; Xu, Z. S.; Ni, M.; Liu, S. 2010. Generalized aggregation operators for intuitionistic fuzzy sets, International Journal of Intelligent Systems 25(1): 1-30. http://dx.doi.org/10.1002/int.20386

Zhou, L. G.; Chen, H. Y. 2010. Generalized ordered weighted logarithm aggregation operators and their applications to group decision making, International Journal of Intelligent Systems 25(7): 683-707. http://dx.doi.org/10.1002/int.20419

Zhou, L. G.; Chen, H. Y. 2011. Continuous generalized OWA operator and its application to decision making, Fuzzy Sets and Systems 168(1): 18-34. http://dx.doi.org/10.1016/j.fss.2010.05.009

Zhou, L. G.; Chen, H.Y. 2012. A generalization of the power aggregation operators for linguistic environment and its application in group decision making, Knowledge-Based Systems 26: 216-224. http://dx.doi.org/10.1016/j.knosys.2011.08.004

Zhou, L. G.; Chen, H. Y.; Liu, J. P. 2011. Generalized multiple averaging operators and their applications to group decision making, Group Decision and Negotiation 22(2): 331-358.

http://dx.doi.org/10.1007/210726-011-9267-1 
Zhou, L. G.; Chen, H. Y.; Liu, J. P. 2012a. Generalized power aggregation operators and their applications in group decision making, Computers \& Industrial Engineering 62(4): 989-999. http://dx.doi.org/10.1016/j.cie.2011.12.025

Zhou, L. G.; Chen, H. Y.; Merigó, J. M.; Gil-Lafuente, A. M. 2012b. Uncertain generalized aggregation operators, Expert Systems with Applications 39(1): 1105-1117. http://dx.doi.org/10.1016/j.eswa.2011.07.110

José M. MERIGÓ has a MSc and a PhD degrees in Business Administration from University of Barcelona, Spain. His PhD received the Extraordinary Award from the University of Barcelona. He also holds a Bachelor's Degree in Economics and a Master's Degree in European Business Administration and Business Law from Lund University, Sweden. He is an Assistant Professor in the Department of Business Administration at the University of Barcelona. He has published more than 200 papers in journals, books and conference proceedings including journals such as Information Sciences, International Journal of Information Technology and Decision Making, Technological and Economic Development of Economy, Expert Systems with Applications, International Journal of Intelligent Systems, International Journal of Uncertainty, Fuzziness and Knowledge-Based Systems, Cybernetics \& Systems, Computers \& Industrial Engineering, Applied and Computational Mathematics, International Journal of Computational Intelligence Systems and International Journal of Fuzzy Systems. He has published 8 books including one edited with World Scientific "Computational Intelligence in Business and Economics" and three with Springer. He is on the editorial board of several journals including the Journal of Advanced Research on Fuzzy and Uncertain Systems and the ISTP Transactions of Systems \& Cybernetics. He has participated in several scientific committees and serves as a reviewer in a wide range of journals. He is currently interested in aggregation operators, decision making and uncertainty.

Kurt J. ENGEMANN is a Full Professor in the Department of Information Systems at Hagan School of Business at Iona College (New Rochelle, New York, USA). He holds a PhD in Operations Research from New York University. He is also the Director of the Center for Business Continuity and Risk Management (BCRM) at Iona College. He has consulted professionally over the past thirty years in the area of risk management and decision modelling for major organizations and has been instrumental in the development and implementation of comprehensive business continuity management programs. He is a Certified Business Continuity Professional (CBCP) with the Disaster Recovery Institute International. He has published more than 150 publications in journals, books and conference proceedings including journals such as International Journal of Intelligent Systems, Interfaces, International Journal of General Systems and International Journal of Uncertainty, Fuzziness and Knowledge-Based Systems. He has published several books and has participated in a wide range of scientific committees. He is the editor-in-chief of the International Journal of Technology, Policy and Management and the International Journal of Business Continuity and Risk Management. He has served as a reviewer in a wide range of journals.

Daniel PALACIOS-MARQUÉS is an Associate Professor of Management at the Technical University of Valencia, Spain. He has an MBA and a PhD in Quality Management and Business Administration. He has published articles in journals such as Tourism Management, Annals of Tourism Research, Small Business Economics, Management Decision, International Journal of Technology Management, Cornell Quarterly Management, Services Industries Journal, Service Business, International Entrepreneurship and Management Journal, Journal of Knowledge Management, Journal of Intellectual Capital, International Journal of Innovation Management and International Journal of Contemporary Hospitality Management. He has been Editor of the book Connectivity and Knowledge Management in Virtual Organizations, Networking and Developing Interactive Communications. 